\title{
Stability Product Identifier Terminology
}

National Cancer Institute

\section{Source}

National Cancer Institute. Stability Product Identifier Terminology. NCI Thesaurus. Code C96072.

Terminology developed to support Product Identifiers within the Stability Data Standards. 